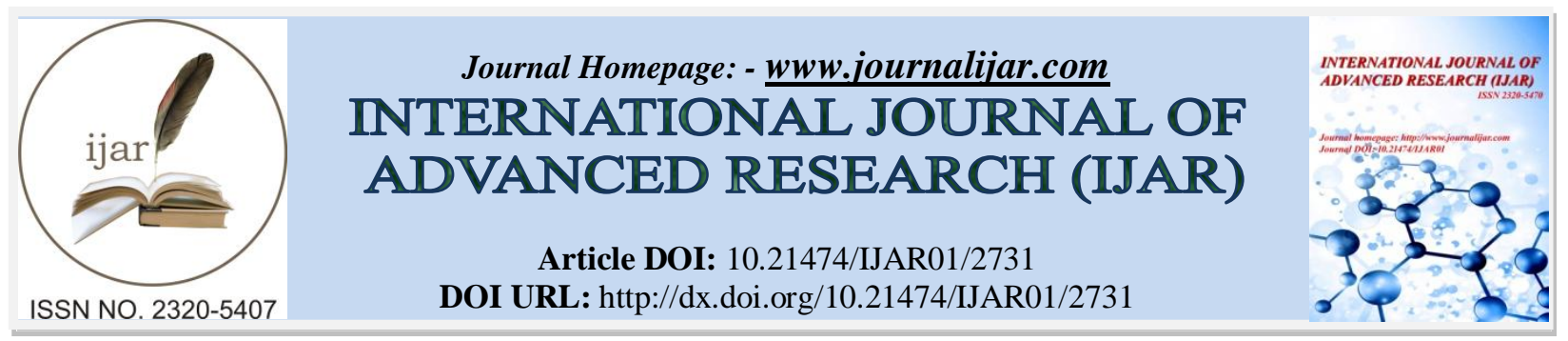

ORIGINAL RESEARCH ARTICLE

\title{
SMOKING PATTERN IN A GROUP OF TUBERCULOSIS PATIENTS, EXPERIENCE OF A MEDICAL COLLEGE HOSPITAL OF BANGLADESH.
}

\author{
Abu Khalid Muhammad Maruf Raza ${ }^{1}$, Muhammad Rafiqul Islam ${ }^{2}$, Mahfujun Nahar ${ }^{3}$ and Zaman Ahmed ${ }^{4}$. \\ 1. Assistant Professor of Pathology, Jahurul Islam Medical College, Kishoregonj, Bangladesh. \\ 2. Registrar, National Institute of ENT, Dhaka, Bangladesh. \\ 3. Medical Officer, Jahurul Islam Medical College Hospital, Kishoregonj, Bangladesh. \\ 4. Assistant Professor of Pathology, Abdul Malek Ukil Medical College, Noakhali, Bangladesh.
}

\section{Manuscript Info}

\section{Manuscript History}

Received: 15 November 2016

Final Accepted: 17 December 2016

Published: January 2017

Key words:-

Tuberculosis; Smoking pattern; DOTS-

Directly Observed Therapy.

\section{Abstract}

Background: Tuberculosis is among the major causes of illness and death worldwide especially in Asia. Smoking is associated with recurrent tuberculosis and its related mortality. Also, it could affect clinical manifestations, bacteriological conversion and outcome of treatment. This study aimed to evaluate the pattern of tobacco smoking, history of previous quit attempts and attitude towards quitting in tuberculosis patients.

Materials and Methods: It was a cross-sectional study done amongst tuberculosis patients coming to DOTS corner of Jahurul Islam Medical College Hospital. 630 patients were included in the study over the period of two years. Data was collected according to the standard questionnaires of smoking pattern.

Results: Sixty one percent $(61 \%)$ patients $(n=384)$ were smoker before the diagnosis of tuberculosis. 50.8\% were current smokers at the time of interview and were continuing smoking after the diagnosis of tuberculosis. Only $10.2 \%$ discontinued smoking after diagnosis. $68.2 \%$ smokes smokes less than 10 cigarettes per day. $53.1 \%$ was between $31-50$ age group. $21-30$ is the commonest age group (62\%) to start smoking. To reduce stress was the most common cause to continue smoking (48.9\%). $71.9 \%$ smokers showed keen interest to stop smoking.

Conclusion: Considering the prevalence of smoking in tuberculosis patients, evaluation of tobacco smoking status in these group of patients and motivating them to quit smoking could be considered as important steps in their treatment process.

Copy Right, IJAR, 2016,. All rights reserved.

\section{Introduction:-}

Tuberculosis is amongst the most common causes of morbidity and mortality in the world especially in Asia. In 2006, 9.2 million new tuberculosis cases and 1.7 million deaths due to tuberculosis were reported globally. ${ }^{1}$ On the other hand, cigarette smoking is amongst the most preventable causes of mortality and the second cause of death worldwide. At present, smoking is the cause of one out of every 10 deaths that occur. According to the WHO

Corresponding Author:- Dr. Abu Khalid Muhammad Maruf Raza.

Address:- Assistant Professor of Pathology, Jahurul Islam Medical College, Kishoregonj, Bangladesh. 
estimates, the rate of morbidity and mortality due to tobacco consumption will reach 8 million by the year $2030 .^{2}$ However, the growing trend of tobacco consumption among adolescents and the youth has been worrisome.

A correlation between tobacco smoking and tuberculosis was suggested and confirmed by multiple studies and has become the center of attention during the recent years. ${ }^{3}$ Current studies have highlighted several correlations between cigarette smoking and tuberculosis infection. ${ }^{4}$ Tobacco consumption is directly correlated with recurrence and disability due to tuberculosis. Also, cigarette smoking impacts clinical manifestations, bacteriologic conversion and treatment outcome of disease. ${ }^{5}$ In other words, one of every 5 deaths due to tuberculosis could have been prevented if the patient was not a smoker. ${ }^{6}$ That is why tuberculosis patients should be a target of smoking cessation programs. Disease recurrence is one of the most important challenges encountered during the course of treatment in tuberculosis patients. Treatment compliance is another important factor for successful treatment of tuberculosis. Absence from work in smoker tuberculosis patients may be due to their nicotine addiction. So, By Collecting information regarding the pattern of tobacco smoking and prevalence of smoking, our knowledge can be enhanced in order to prevent and control cigarette smoking.

\section{Materials and Method:-}

This was a cross-sectional study conducted over a period of two years time from July 2014 to June 2016. All patients presented to the DOTS Corner of Jahurul Islam Medical College Hospital during this time period entered the study. Data were collected by trained technicians through face to face interview with patients. Only patients who were fully alert and conscious were included in the study after obtaining a written informed consent from them. Data regarding age of initiation of smoking, pattern of smoking, the first experience of cigarette offering, quit attempts and number of cigarettes they smoked per day was collected and entered the questionnaires.

\section{Statistical analysis:-}

Survey data were analyzed using the Statistical Package for Social Sciences (SPSS Inc, Chicago, IL, USA). The numbers of cigarettes smoked were numerically added together to obtain an aggregate score of the quantity smoked daily. Descriptive statistical analyses were performed by using Microsoft Excell 2007 software.

\section{Results:-}

Among the 630 tuberculosis patients coming to DOTS corner for taking drugs, 384 patients (61\%) found as smoker before diagnosis of tuberculosis. Despite of diagnosis of tuberculosis almost half of the patients (50.8\%) were continuing smoking. Only a few numbers of patients $(10.2 \%)$ discontinued smoking after diagnosis of tuberculosis. 246 tuberculosis patients were found non smoker (Table 1).

Table1:- Current smokers among tuberculosis patients $(\mathrm{n}=630)$.

\begin{tabular}{|c|c|c|}
\hline Current smoking status & Number & Percentage \\
\hline Continuing smoking & 320 & $50.8 \%$ \\
\hline Discontinuing smoking & 64 & $10.2 \%$ \\
\hline Non smoker & 246 & $39 \%$ \\
\hline Total & 630 & $100 \%$ \\
\hline
\end{tabular}

Among the 384 tuberculosis patients who were smoker before diagnosis of Tuberculosis, $68.2 \%(\mathrm{n}=262)$ smoked less than 10 cigarettes per day. Other $21.4 \%$ smoked more than 10 cigarettes and $10.4 \%(n=40)$ smoked more than 20 cigarettes per day (Table 2).

Table 2:- Distribution of smokers based on number of cigarettes smoked per day.

\begin{tabular}{|c|c|c|}
\hline Number of Cigarettes & Number of Patients & Percentage \\
\hline$<10$ & 262 & $68.2 \%$ \\
\hline $10-20$ & 82 & $21.4 \%$ \\
\hline$>20$ & 40 & $10.4 \%$ \\
\hline Total & 384 & $100 \%$ \\
\hline
\end{tabular}

We found that, younger age group are the most vulnerable for smoking in tuberculosis. More than half (53.1\%) were in the age group 31-50 years. Older age people (>50 years) had less smoking (10.9\%) compared to younger age group (Table 3). 
Table 3:- Age wise distribution of number of smoker in Tuberculosis.

\begin{tabular}{|c|c|c|}
\hline Age group & Number & Percentage \\
\hline$<30$ & 138 & $36 \%$ \\
\hline $31-50$ & 204 & $53.1 \%$ \\
\hline$>50$ & 42 & $10.9 \%$ \\
\hline Total & 384 & $100 \%$ \\
\hline
\end{tabular}

Younger age groups are more prone to start smoking habit. 21-30 years age group were the commonest group to start smoking in tuberculosis patients. $28.1 \%$ started smoking before the age of 20. Only 14 tuberculosis started smoking after the age 40 (Table 4).

Table 4:- Age distribution of smokers based on initiation of smoking.

\begin{tabular}{|c|c|c|}
\hline Starting Age Group & Number & Percentage \\
\hline$<20$ & 108 & $28.1 \%$ \\
\hline $21-30$ & 238 & $62 \%$ \\
\hline $31-40$ & 24 & $6.3 \%$ \\
\hline$>40$ & 14 & $3.6 \%$ \\
\hline Total & 384 & $100 \%$ \\
\hline
\end{tabular}

Among the 384 tuberculosis patients who were smoker before diagnosis of Tuberculosis, most of the patients smoked for a long period of time before diagnosis of tuberculosis. $66.1 \%$ smoked for at least 10 years. 118 patients smoked around 10-20 years. Only 12 patients smoked for more than 20 years (Table 5).

Table 5:- Distribution of smokers based on number of years smoked.

\begin{tabular}{|c|c|c|}
\hline Years smoked & Number & Percentage \\
\hline$<10$ & 254 & $66.1 \%$ \\
\hline $10-20$ & 118 & $30.8 \%$ \\
\hline$>20$ & 12 & $3.1 \%$ \\
\hline Total & 384 & $100 \%$ \\
\hline
\end{tabular}

This study also explored the reasons of continuing smoking after the diagnosis of tuberculosis. Patients said multiple reasons for the smoking. To reduce stress (48.9\%) were the commonest cause to continue smoking. 156 patients smoked only to get pleasure. People's influences, self confidence, enhance work performance were the other common causes (Table 6).

Table 6:- Reason to continuing Smoking after tuberculosis diagnosis.

\begin{tabular}{|c|c|c|}
\hline Reasons & Number & Percentage \\
\hline Reduce stress & 188 & $48.9 \%$ \\
\hline To get pleasure & 156 & $40.6 \%$ \\
\hline Peer pressure & 108 & $28.1 \%$ \\
\hline Self confidence & 66 & $17.2 \%$ \\
\hline Enhance work performance & 62 & $16.1 \%$ \\
\hline
\end{tabular}

*Allowed to answer multiple reasons.

Among the tuberculosis patients who are smoker or continue smoking came to DOTS corner for taking drugs, a good number of patients (71.9\%) showed interest to quit smoking after diagnosis of Tuberculosis. 66 (17.2\%) patients showed good will to quit smoking in recent days. Only few patients $(10.9 \%)$ showed no confidence to quit smoking (Table 7).

Table 7:- Smokers future plan to quit smoking.

\begin{tabular}{|c|c|c|}
\hline Future plan to quit & Number & Percentage \\
\hline Interest to quit & 276 & $71.9 \%$ \\
\hline Will attempt to quit & 66 & $17.2 \%$ \\
\hline Not confident & 42 & $10.9 \%$ \\
\hline Total & 384 & $100 \%$ \\
\hline
\end{tabular}




\section{Discussion:-}

Apart from HIV/AIDS, tobacco smoking is the only major cause of death that is increasing rapidly. It is estimated that smoking will cause about 10 million adult deaths from all causes in 2030 and most of the increased tobaccorelated deaths will take place in Asia, Africa and South America. ${ }^{7}$ Long term inhalation of tobacco smoke alters a wide range of immunological functions, resulting in significantly increased risk of heart disease, lung cancer, microbial infections and delayed recovery from these diseases. ${ }^{\mathbf{8}}$ Though the underlying biological mechanism is unclear, strong associations between tobacco smoking and TB have been proved in several areas.

Our study results revealed the fact that many of tuberculosis patients are active or occasional smokers. And they keep continuing smoking even after diagnosis of TB. In a study conducted by Gullón Blanco and colleagues on the impact of smoking on sputum smear of tuberculosis patients, $64 \%$ of patients were smokers. ${ }^{4}$ In our study $70 \%$ of the patients are smoker and $50.8 \%$ of them continue smoking after diagnosis of TB under treatment. As a significant number of patients continue smoking, smoking cessation interventions by the medical staff implementing the DOTS seems necessary. In a study conducted in Indonesia it was shown that $72 \%$ of tuberculosis patients had tobacco consumption. By using smoking cessation interventions, this rate decreased to $11 \%$ at the time of next visit. ${ }^{6}$

The younger age group are the most vulnerable for smoking in tuberculosis in this study. $36 \%$ patients are less than 30 years age group with more than half $(53.1 \%)$ are in the age group of 31-50 years. Younger age groups are more prone to start smoking habit. 21-30 years age group were the commonest group to start smoking in tuberculosis patients. This study also explored the reasons of continuing smoking after the diagnosis of tuberculosis. To reduce stress $(48.9 \%)$ were the commonest cause to continue smoking. This stress factor may be the cause for starting smoking in the early age group patients as this group is more vulnerable for educational, personal and employment issues. It should be noticed that behavior of tobacco use is very difficult to change, even with medicinal aids for cessation. Only a small proportion of smokers stop smoking successfully on their own. ${ }^{\mathbf{1}}$ In this study, the patients who are smoker or continue smoking came to DOTS corner for taking drugs, a good number of patients (71.9\%) showed interest to quit smoking after diagnosis of Tuberculosis. 66 (17.2\%) patients showed good will to quit smoking in recent days.

Considering the prevalence of tobacco consumption among tuberculosis patients, evaluation of the cigarette smoking status and encouraging them to quit play an important role in control and treatment of tuberculosis. ${ }^{\mathbf{1 0}}$ Adding behavioral studies and nicotine replacement therapies to the DOTS can result in faster recovery, shorter infectious period and prevent treatment failure. ${ }^{\mathbf{1 1}}$ Prevention of tobacco consumption and encouraging people to stop smoking can decrease the incidence of clinical cases of tuberculosis and related deaths. ${ }^{\mathbf{1 2}}$

\section{Conclusion:-}

Tuberculosis and tobacco smoking epidemics are continuing their growing trend in developing countries. In this respect, merging the two systems suggested by the WHO namely DOTS for tuberculosis and MPOWER ${ }^{2}$ for tobacco control and enhancing each one by the other can be a great strategy for controlling these obstacles. By promoting smoking cessation in TB patients, we can increase patients compliance to treatment, improve their interpersonal and social communications, decrease their stress and control their risky behaviors.

\section{Conflict of interest:-}

All the authors declared no competing interest. 


\section{References:-}

1. WHO report 2008, Global tuberculosis control surveillance, planning, financing. www.who.int/tb/publications/global_report/2008/pdf/fullreport.pdf.

2. WHO report on the global tobacco epidemic, 2008. The MPOWER Package. http://www.who.int/tobacco/ mpower/en/index/html.

3. Mohammad K, Noorbala AA, Majdzadeh SR, Karimloo M. Trends of Prevalence of Tobacco consumption in Iran (1370- 78). According to two National Health and disease projects. Hakim Journal. 2000; 197: 290- 294.

4. Gullón Blanco JA, Suárez Toste I, Lecuona Fernández M, Galindo Morales R, Fernández Alvarez R, Rubinos Cuadrado $\mathrm{G}$ et al. Tobacco smoking and sputum smear conversion in pulmonary tuberculosis. Med Clin (Barc). 2007; 128 (15): 565- 568.

5. Slama K, Chiang CY, Enarson DA. Educational series: Tobacco and Tuberculosis. Tobacco cessation intervention for tuberculosis patients. Int J Tuberc Lung Dis. 2007; 11(6): 612- 616.

6. Abal AT, Jayakrishnan B, Parwer S, El Shamy A, Abahussain E, Sharma PN. Effect of cigarette smoking on sputum smear conversion in adults with active pulmonary tuberculosis. Respir Med. 2005; 99 (4): 415- 420.

7. Peto R, Chen ZM, Boreham J. Tobacco - the growing epidemic. Nat Med 1999, 5(1):15-17.

8. Sopori M: Effects of cigarette smoke on the immune system. Nat Rev Immunol 2002, 2(5):372-377.

9. Chiang CY, Slama K, Enarson DA: Tobacco use and tobacco control. Int J Tuberc Lung Dis 2007, 11(4):381385.

10. Gajalakshmi V, Peto R, Kanaka TS, Jha P. Smoking and mortality from tuberculosis and other diseases in India: Retrospective study of 43000 adult male deaths and 35000 controls. Lancet. 2003; 362 (9383): 507- 515.

11. Thomas A, Gopi PG, Santha T, Chandrasekaran V, Subramani R, Selvakumar N et al. Predictors of relapse among pulmonary tuberculosis patients treated in a DOTS program in South India. Int J Tuberc Lung Dis. 2005; 9 (5): 556- 561.

12. El Sony A, Slama K, Salieh M, Elhaj H, Adam K, Hassan A et al. Feasibility of brief tobacco cessation advice for tuberculosis patients: A study from Sudan. Int J Tuberc Lung Dis. 2007; 11 (2): 150155. 